\title{
The Application of Quality Function Deployment for the Development of Rubber Sheet Machine
}

\author{
Phanuwat Wongsangnoi ${ }^{1 *}$, Nalin Pianthong ${ }^{1}$ and Nattadon Pannucharoenwong ${ }^{2}$ \\ ${ }^{1}$ Department of Industrial Engineering, Faculty of Engineering, Ubon Ratchathani University, 34190 Thailand. \\ ${ }^{2}$ Department of Mechanical Engineering, Faculty of Engineering,Thammasat University, 12120 Thailand.
}

\begin{abstract}
This research aims to find suitable ways to develop a rubber flat sheet extrusion machine. To meet the needs of customers by applying qualitative distribution techniques by exploring the needs of The sample farmers in the 4 provinces with a large amount of rubber flat sheet production in the Northeastern region are Sakon Nakhon Province, Nakhon Phanom Province, Mukdahan Province and Bueng Kan Province, which have two operating procedures, Part 1. Is to collect customer requests by interviewing Then group the customer demand factors with a link group chart to bring out the questionnaire and to find the weight score of the importance of each factor of the development of rubber sheet extrusion machine Part 2 is to build a quality house to find technical requirements. Relationship between technical specifications and the relationship between customer demand factors and technical requirements. By scoring the correlation and ranking the result was the time of extruding the rubber. The weight was 131.2 , the relative priority (\% Relative) 7.99 , the thickness-thin adjustment was 118.5 , the relative importance (\% Relative) 7.22 and the size of the rubber sheet. The weight was 114.4 priority by comparison (\% Relative) 6.98 , respectively.
\end{abstract}

Keywords

Development of rubber sheet machine; product development; quality function deployment

\section{Introduction}

Successful and innovative product (or service) development is highly correlated with the company's success and reason for existence. It is imperative that a company's main purpose for existing is to provide goods and/or services to meet and even exceed the expectations of their customers. In order to be successful, companies must choose goods and/or services in which to establish a competitive advantage, and by doing so, differentiate themselves from their competitors. [1]Increasing complexity in new product development (NPD) is a common concern in both academic and industrial practice, resulting in a growing body of new and updated innovation methodologies.[2-3]Quality function deployment (QFD) is a well-established and particularly powerful methodology providing a systematic procedure for assuring product designs and production processes are driven by customer requirements. QFD rests on the ability to make effective design trade-offs, which are central to decision-making. [4-5]The innovative product life cycle is the main subject of the new product development (NPD) framework. In this context, the QFD methodology can be used in order to avoid the development of a new product that will not be a success on market and to minimize the costs of development. This represents a tool that can help companies to successfully develop new products or to improve the existing ones through a series of innovation related steps, starting from the process of idea generation and ending at the launch of the product into the market. [6]Quality function deployment (QFD) techniques are techniques that help design and improve the quality of products to meet customer needs. It is a technique that focuses on customer satisfaction and customer focus by taking feedback from customers to study and identify their true needs. And find a way to do it to achieve such requirements appropriately, the mistakes in the new products of the quality do not meet customer needs. Helps to shorten the product development time It is also possible to avoid design changes while production has begun, as well as enabling teamwork as decisions are largely based on consensus. Therefore, a common goal was formed 
All members contribute to feedback on the development of new products. In cooperation with to be smooth and accuracy in product design and manufacturing operation. [7-9]In addition to the design and manufacture of souvenirs, quality houses are applied. (House of quality; HOQ), which is a matrix in QFD, was used to develop packaging of milled rice as a souvenir. To link customer needs to design Products by assessing customer satisfaction It was found that $83.11 \%$ of the original products were wedding favours and $79.76 \%$ were gifts or souvenirs. This technique contributes to product and packaging development. Packaging to meet the needs of users[10] For research work related to Pottery QFD technique was applied to the design and development of automatic pottery wheels for Small Enterprise Small and small in Indiaby collecting data and then converting customer needs. It comes as a technical specification. Before designing and developing automatic pottery wheels in the design also Consider other issues including the mechanism of the machine. Usability, safety and ergonomics. [11]For other industries such as the food industry, durian chips have been developed using the QFD technique by converting customer needs into technical requirements for improving and developing the quality of durian chips. Found that 5 features The important quality of fried durian Which is the requirement of customers such as having a natural smell, crispy, thin sheet style, no rancid smell It has a natural flavour and when converted to technical requirements that need to be improved, it was found that the top five technical requirements were baking after frying and baking before customer or retail delivery, packaging development and improvement. Variety of flavour enhancements The retention period is appropriate and the grading of the durian.[12]At present, the rubber plantation profession can be an export product and make a lot of income into the country, but at present, the rubber production process is still very difficult and takes a long time and the product quality is not good enough as the market needs and in Manufacturing still requires labour in every step of the production. This makes gardeners have little time to rest and do not have time to do additional professions for income besides rubber production. For this reason, the idea was to create a semi-automatic rubber calendar to replace human labour. And reduce the production time of rubber So that farmers have more time to do additional jobs to have more income to support the family.

This research focuses on the application of qualitative functional distribution techniques to guide the development of smooth rubber products. To meet the needs of customers Including adding product value Promote local products for sustainable development and will continue to be needed in both domestic and international markets.

\section{Research objectives}

To find a way to develop rubber sheet machine to meet the needs of customers for both domestic and international sales. By applying quality function deployment techniques.

\section{Product design and development process}

In practice, product design and development processes are often non-sequential. Each step has absolutely no beginning and ending. In fact, these activities are born Overlapping and repeating over time, as in Fig. 1, there is a reverse dashed arrow indicating the uncertainty of progress. We may find that information comes up in a particular step, or the results of a particular process may require the team to revert to one activity before moving on. The process is economic analysis. Comparison with competing products Building and testing models and prototypes 


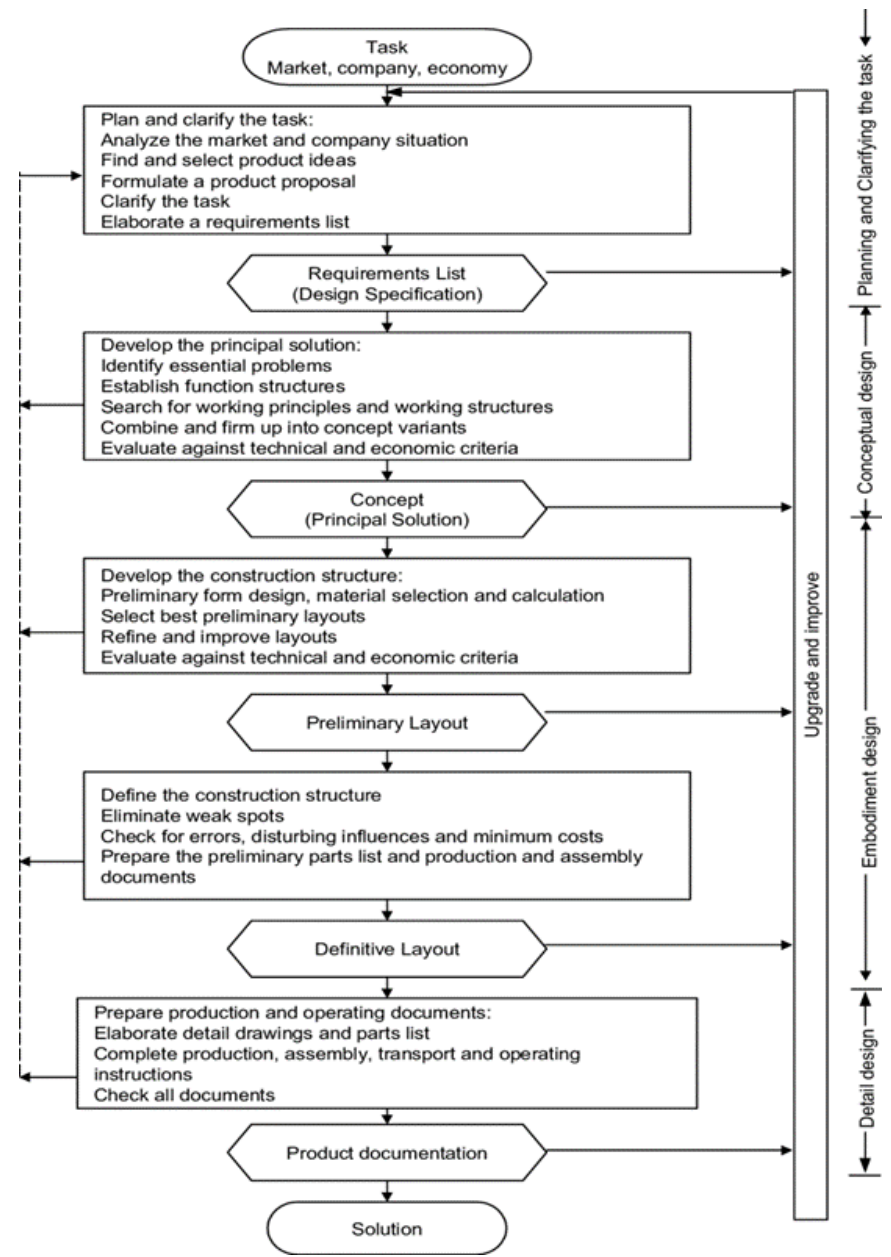

Figure 1. Steps in the Planning and Design Process [13]

\section{Research method}

\section{Quality Function Deployment: QFD}

Voice of Customer: VOC by surveying customer demand for rubber sheet products with group meeting techniques. From the sample farmers in the 4 provinces with a large amount of rubber flat sheet production in the Northeastern region, namely Sakon Nakhon Province, Nakhon Phanom Province, Mukdahan Province, and Bueng Kan Province, as the target group of rubber processors and buyers. A total of 85,058 individuals categorized the same desirable factors or desires. To be the same requirement They were then organized into categories with group charts, linking and analyzing the initial needs of customers towards flat rubber products using a tree chart to collect similar or duplicate needs into categories.
The results were analyzed by using sensory testing using Hedonic Scale Method questionnaire, which is the most commonly used method for customer acceptance testing. [14]And random sampling The target group of buyers of smooth rubber products was used by the tester to observe and assess the overall picture with a questionnaire with a scale of approximately $1-5$ (5-Point Hedonic Scale). 85,058 sets of data were collected from the sample farmers in the district. The four provinces with a large amount of rubber flat sheet production in the Northeast Region are Sakon Nakhon Province, Nakhon Phanom Province, Mukdahan Province, and Bueng Kan Province by using the method of calculating the number of samples from the sample size tables of Taro Yamane. At 95\% confidence level, tolerance size $+5 \%$ population size $>100,000$ people. [15]And calculating the score obtained from the questionnaire using Geometric Mean as equation 1 , which is the most reliable means It is often used with data from questionnaires that are characterized as a grade selection. From the information received.

$$
\text { Geometric Mean }=\left(\mathrm{N}_{1} * \mathrm{~N}_{2} * \mathrm{~N}_{3} * \ldots * \mathrm{~N}_{\mathrm{n}}\right)^{1 / \mathrm{n}}
$$

$\mathrm{N}=$ The value of the information obtained from thequestionnaire.

\section{$1,2,3, \ldots, \mathrm{n}=$ Amount of data}

\section{House of Quality: HOQ}

According to the process of doing the QFD technique, the analytical tool is used, House of Quality. 


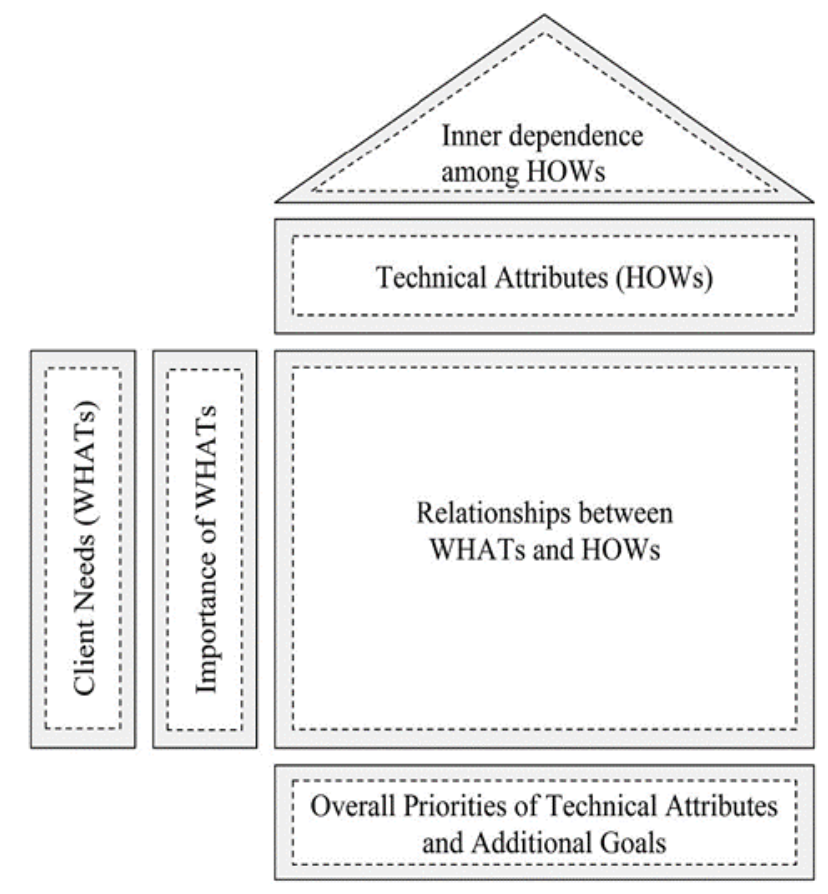

Figure 2. House of Quality[16]

The results of the Customer Demand Survey and the Importance Rating (IMP) of the product are then considered by converting them into technical specifications. That can meet the needs of customers Finding the relationship between technical specifications and customer requirements with technical requirements. It is written in the form of a correlation matrix and is used to indicate the degree of relationship [17] Level (AI) by converting the symbol to the correlation score. Then multiplied by the highest score for each factor of demand (IMP) of the smooth rubber sheet machine as equation 2

$\mathrm{AI}=\sum$ (Relationship between technical requirements and customer needs $\mathrm{x}$ IMP) (2)

And to find the weight of significance ( $\%$

Relative) which is calculated as equation 3

$$
\% \text { Relative }=\left(\mathrm{AI} / \sum \mathrm{AI}\right) \times 100
$$

And prioritize the technical requirements and select the top 5 technical requirements with the highest\% Relative value as a guideline for the development of rubber sheet machine.

\section{Research results}

\section{Results of the application of Quality function deployment}

From collecting the voice of customer requests to obtain the factors of customer demand for rubber flat sheet presses. This makes it known to the characteristics that the customer is satisfied with and what to expect in the flat rubber products. It is a fact finding out from customers in terms of their attitude towards smooth rubber products on the general market. Which can summarize the needs of 19 factors as follows

1. Can press rubber continuously.

2. No vibration in use.

3. Can be ironed as required.

4. The speed can be adjusted.

5. Can iron sheets to a uniform size.

6. Can be ironed in a long time.

7. Can adjust the distance of the ball print pattern.

8. Can adjust the rolling ball accordingly.

9. Can be easily controlled in the work.

10. Can be used with household electrical system.

11. There is safety while working.

12. There is a manual that is easy to read and understand before working.

13. Easy repair and maintenance of materials

14. Disassemble and assemble equipment to work.

15. The structure of the machine is strong.

16. Have a weight suitable for work.

17. The size of the machine is suitable for use.

18. The machine is suitable, can be moved easily.

19. The price is reasonable for the sample.

Group customer needs Which can be grouped into two groups of customer demand factors: the functionality of the machine and the shape and size of the machine for marketing, it consists of the price of the machine. As for the machine side, the rubber sheet extrusion consists of rubber extrusion time / adjustment of the thickness - thin / size of rubber sheet. Physical feature Raw materials are standard sizes with both groups comprising 19 factors of sub-customer demand.

Bring data on the needs of rubber sheet extrusion machine. Come to do a questionnaire with the target customers. To determine the 
importance of weight score for each factor. By dividing the questionnaire into 3 parts

Part 1 General information of respondents The survey of the behavior of rubber processing farmers towards the rubber flat sheet press was used by coincidentally sampling with a group of farmers in 4 provinces, namely Sakon Nakhon Province. Nakhon Phanom Province Mukdahan and Bueng Kan Province, which has 85,058 members, referring to the table showing population and sample numbers of [18]The target group was less than 100,000 people, therefore, 384 target groups were required to collect data, found that most of them were male, 62.37 percent, age 35-44, 42.21 percent, high school education, 57.38 percent were farmers / private businesses. 68.25 each with monthly income in the range 10,001-20,000 baht, 34.28\%, taking into account the daily processing volume of $83.25 \%$, the products processed are rubber $78.73 \%$, selling products that are processed from rubber by themselves, $80.67 \%$ sell products that are processed from rubber, 1 - per week 2 times, $53.25 \%$, the interest in the rubber flat sheet extrusion machine $87.50 \%$ If the rubber flat sheet press has a prototype, there is a need to try out $85.67 \%$. In addition to the traditional rubber products processing then Most farmers need tools or inventions. To help reduce the working time of 62.38 percent.

Part 2, the level of demand for each factor toward the rubber flat sheet extruder and the third part, the satisfaction level of each factor affecting the rubber flat sheet extruder, were found. Weight score of each factor requirement of rubber flat sheet extrusion machine Shown as in Table 1

Table 1. Weight score of each factor requirement of rubber flat sheet extrusion machine

\begin{tabular}{|c|c|c|}
\hline No & Customer requirement & $\begin{array}{c}\text { Level of } \\
\text { importance } \\
\text { (IMP) }\end{array}$ \\
\hline 1 & $\begin{array}{c}\text { Can continuously press } \\
\text { rubber. }\end{array}$ & 4.36 \\
\hline
\end{tabular}

\begin{tabular}{|c|c|c|}
\hline 2 & There is no vibration in use. & 4.16 \\
\hline 3 & Can be ironed as required. & 4.26 \\
\hline 4 & Can adjust the speed. & 4.12 \\
\hline 5 & $\begin{array}{l}\text { Able to iron sheets to a } \\
\text { uniform size. }\end{array}$ & 4.30 \\
\hline 6 & Can be ironed in a long time. & 4.16 \\
\hline 7 & $\begin{array}{l}\text { Can adjust the distance of the } \\
\text { ball with pattern print. }\end{array}$ & 4.43 \\
\hline 8 & $\begin{array}{c}\text { The ball can be adjusted } \\
\text { accordingly. }\end{array}$ & 4.46 \\
\hline 9 & $\begin{array}{c}\text { Can be easily controlled in } \\
\text { the work. }\end{array}$ & 4.43 \\
\hline 10 & $\begin{array}{c}\text { It can be used with a } \\
\text { household electrical system. }\end{array}$ & 4.64 \\
\hline 11 & $\begin{array}{l}\text { There is safety while } \\
\text { working. }\end{array}$ & 4.23 \\
\hline 12 & $\begin{array}{l}\text { There is a manual that is } \\
\text { easy to read before working. }\end{array}$ & 4.08 \\
\hline 13 & $\begin{array}{l}\text { Easy to repair and maintain } \\
\text { materials. }\end{array}$ & 4.12 \\
\hline 14 & $\begin{array}{c}\text { Can disassemble and } \\
\text { assemble equipment to work. }\end{array}$ & 4.18 \\
\hline 15 & $\begin{array}{l}\text { The structure of the machine } \\
\text { is strong. }\end{array}$ & 4.22 \\
\hline 16 & $\begin{array}{c}\text { Has a weight suitable for } \\
\text { work. }\end{array}$ & 4.03 \\
\hline 17 & $\begin{array}{l}\text { The size of the machine is } \\
\text { suitable for use. }\end{array}$ & 4.35 \\
\hline 18 & $\begin{array}{l}\text { The machine is suitable, can } \\
\text { be moved easily. }\end{array}$ & 3.98 \\
\hline 19 & $\begin{array}{c}\text { The price is reasonable for } \\
\text { the sample. }\end{array}$ & 3.92 \\
\hline
\end{tabular}

\section{results Building house of quality}

Build a quality home schedule by analyzing technical specifications Relationship between technical specifications and the relationship between customer demand factors and technical requirements. In the form of a matrix Using relationship symbols and convert the symbols into Affinity Score It was then multiplied by the weight score of each factor that was the most between the flat rubber calendar and the 
technical specification priorities. As shown in table 2

Choose the technical specification with the top 3 priorities: extrusion time/adjustment of thickness-thin/size of rubber sheet. To be used as a guideline to develop the rubber flat sheet press to meet the needs of the customers as possible.

Table 2. ranked the technical requirements by weight of significance by comparison(\% Relative)

\begin{tabular}{|c|c|c|c|}
\hline No & $\begin{array}{c}\text { Technical } \\
\text { specification }\end{array}$ & $\begin{array}{c}\text { Importance } \\
\text { weight }\end{array}$ & $\begin{array}{c}\text { Priority by } \\
\text { comparison } \\
(\%) \\
\text { Relative })\end{array}$ \\
\hline 1 & $\begin{array}{c}\text { Time for } \\
\text { extrusion of } \\
\text { rubber }\end{array}$ & 131.2 & 7.99 \\
\hline 2 & $\begin{array}{c}\text { Adjustment of } \\
\text { thickness-thin } \\
\text { distance }\end{array}$ & 118.5 & 7.22 \\
\hline 3 & $\begin{array}{c}\text { Size of rubber } \\
\text { sheet }\end{array}$ & 114.4 & 6.98 \\
\hline
\end{tabular}

\section{Discuss and summarize research results}

This research It was found that qualitative function distribution techniques could be applied in the development of rubber flat sheet presses to meet customer needs. By adopting the factors of customer demand in building a quality house (HOQ) to analyze the technical requirements of the priorities and use it as a guideline for the development of the rubber flat sheet press to meet the needs of the customer. most The technical requirements that were introduced in the development were the functionality of the machine. It was obtained by ranking the technical requirements by weight, significance, by comparison (\% Relative) in the first 3 places, namely extrusion time of rubber, adjustment of thickness-thin and size of rubber sheet. The analysis has clearly shown the development of rubber sheet extrusion machine. In order to make the rubber sheet extrusion machine more efficient in work and help reduce the working time of the sample farmers and get the products according to the needs of the customers. 


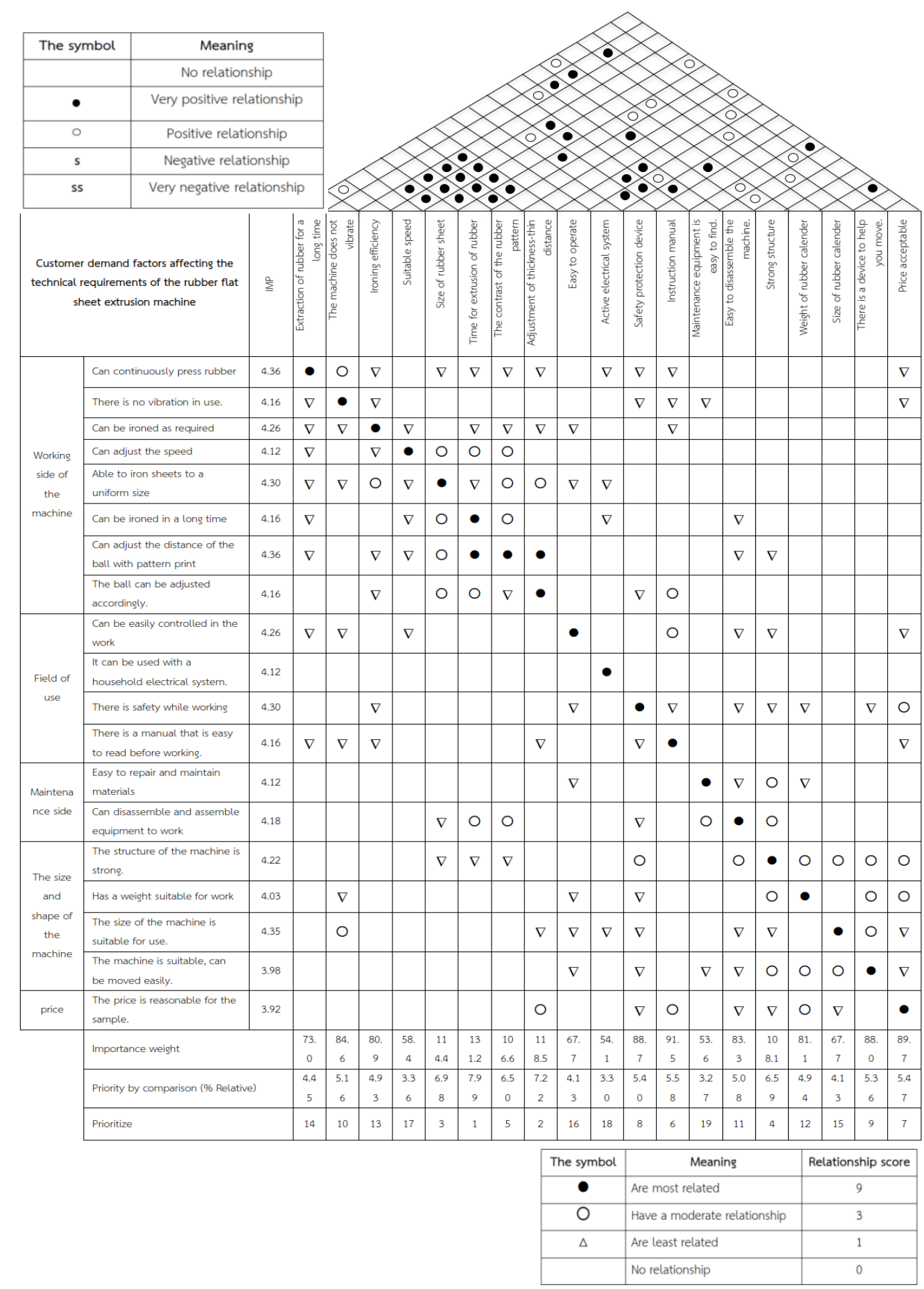

Figure 3. Quality house of rubber flat sheet extrusion machine

\section{Acknowledgment}

The researcher would like to thank the Department of Industrial Engineering. Faculty of Engineering Ubon Ratchathani University to support this research tool. Thank you to all 384 samples for their cooperation in collecting the data. And thank you in many sectors for your support Help and participate in researching this time

\section{References}

[1] Smith, A. D. (2011). Competitive approaches to new product development: A comparison of successful organizations 
in an unstable economic environment. Team Performance Management, 17(3/4), 124-145.

[2] Peng, D. X., Heim, G. R., \& Mallick, D. N. (2014). Collaborative product development: The effect of project complexity on the use of information technology tools and new product development practices. Production and Operations Management, 23, 1421-1438.

[3] Prange, C., Eng, T. Y., \& Li, J. (2015). Collaborative new product alliances: A review of the literature and research perspectives. Strategic Change, 24, 351371.

[4] Altun, K., Dereli, T., \& Baykasoglu, A. (2013). Development of a framework for customer co-creation in NPD through multi-issue negotiation with issue tradeoffs. Expert Systems with Applications, 40, 873-880.

[5] Liu, Y., Zhou, J., \& Chen, Y. (2014). Using fuzzy nonlinear regression to identify the degree of compensation among customer requirements in QFD. Neurocomputing, 142, 115-124.

[6] Andreea Cristina Ionica, Monica Leba. (2 015 ), QFD Integrated in New Product Development - Biometric Identification System Case Study . Procedia Economics and Finance, 23, 986 - 991.

[7] Shih, H.S. \& Chen, S.H. (2013). A Conceptual Design of a Mobile Healthcare Device-An Application of Three-stage QFD with ANP and TRIZ. International Journal of Operations Research, 10(2), 8091.

[8] Mohan, K. R., Lohit, H.S., Manas R. M., \& Basheer, A.Md. (2012). Design of Multipurpose Wheel Chair for Physically Challenged and Elder People. SASTech Journal, 11(1), 107-117.

[9] Ji,P., Jin, J., Wang,T.\& Chen,Y. (2014). QuantificationandIntegrationofKano's Model Into QFD for Optimizing Product
Design.International Journal of Production Research, 52(21), 6335-6348.

[10] Sinthavalai, R. \& Ruengrong, S. (2018). An Application of House of Quality (HOQ) for Designing Rice Product as a Souvenir. Naresuan

University Journal: Science and Technology, 26(3), 36-51.

[11] Patil, Sh.S., Gopinath C. \& Suresha,S. (2016). Design and Development of an Automated Pottery Wheel for MSME. MSRUAS-SASTech Journal, 15(1), 21-24

[12] Joompha, W., \& Pianthong, N. (2018). Development of Durian Chips Product by Apply of Quality Function Deployment. Journal of Science \& Technology, Ubon Ratchathani University, 20(3), 204-218.

[13] Pahl, G., Beitz, W., Feldhusen, J. and Grote, K. H. (2007). Engineering Design: A Systematic Approach. 3 ed. SpringerVerlag London.

[14] Peryam, D.R. and Pilgrim, F.J. ( 1957 ). Hedonic scale method of measuring food preferences.Food Technology.

[15] Yamane, T. ( $\left.\begin{array}{llll}1 & 9 & 7 & 3\end{array}\right)$. Statistics: an Introductory Analysis. Tokyo: Harper International Edition.

[16] S. Eleftheriadis, P. Duffour, D. Mumovic. ( $\left.\begin{array}{llll}2 & 0 & 1 & 8\end{array}\right)$. Participatory decision-support model in the context of building structural design embedding BIM with QFD. Advanced Engineering Informatics, 38, 695-711.

[17] Cohen, L. ( 1995) · Quality Function Deployment How to Make QFD Work for You. Prentice-Hall. New Jersey.

[18] Robert V. Krejcie and Earyle W. Morgan. ( 1970 ). Educational and Psychological Measurement, 608-609 